\title{
Dynamic Characteristics and Chloride Resistance of Basalt and Polypropylene Fibers Reinforced Recycled Aggregate Concrete
}

\author{
Dong Lu $\mathbb{D},{ }^{1,2}$ Hui Cao $\mathbb{D}^{3},{ }^{3}$ Qiangru Shen, ${ }^{3}$ Yue Gong, ${ }^{4}$ Cheng Zhao, ${ }^{1}$ and Xiaohui Yan ${ }^{1}$ \\ ${ }^{1}$ School of Materials Science and Engineering, Chang'an University, Xi'an 710064, China \\ ${ }^{2}$ School of Civil Engineering, Harbin Institute of Technology, Harbin 150000, China \\ ${ }^{3}$ School of Transportation and Civil Engineering, Nantong University, Nantong, Jiangsu 226019, China \\ ${ }^{4}$ State Key Laboratory of Metal Matrix Composites, Shanghai Jiao Tong University, Shanghai 200240, China
}

Correspondence should be addressed to Hui Cao; caohui03@ntu.edu.cn

Received 11 October 2019; Revised 30 December 2019; Accepted 9 January 2020; Published 2 June 2020

Guest Editor: Jinjun Xu

Copyright (C) 2020 Dong Lu et al. This is an open access article distributed under the Creative Commons Attribution License, which permits unrestricted use, distribution, and reproduction in any medium, provided the original work is properly cited.

\begin{abstract}
Fiber polymer has been extensively used to improve the mechanical properties and durability of concrete. However, the studies of the effect of fiber polymer on the dynamic performance of recycled aggregate concrete (RAC) is still very limited. In this study, we prepared two types of RAC formulations: RAC reinforced with basalt fibers (BFs) and RAC reinforced with polypropylene fibers (PPs), and compared the effects of fiber types and contents on the air void content, workability (slump), mechanical properties (compressive and flexural strength), dynamic characteristics (dynamic modulus of elasticity and damping ratio), and chloride resistance of RAC. The experimental results showed that the air void content and slump value decreased with the increase of replacement percentage of RCA and fiber contents. Adding PPs provided a more negative effect on the slump of RAC than BFs. The mixtures containing $0.2 \%$ PPs and BFs both obtained the highest flexural strength. The addition of PPs was more effective than BFs in improving the damping ratio of RAC, and the mixtures containing $0.3 \%$ PPs and BFs both obtained the highest damping ratio. Compared to the RAC without addition of fiber, the charge passed of specimen with addition of PPs approximately increased by $45 \%$, while the specimen with addition of BFs approximately increased by $30 \%$, when the fiber content was $0.3 \%$. This study demonstrates the potential of using fiber to promote the dynamic properties of RAC.
\end{abstract}

\section{Introduction}

Over the past several decades, with the rapid development of the infrastructure industry, especially in developing countries, a large amount of construction and demolition waste $(C \& D W)$ generated [1-4], which not only causes serious pollution to the environment but also leads to waste of nonrenewable resources $[5,6]$. Thus, several researches have begun to investigate and indicate that the application of RCA in RAC is an effective way to reuse C\&DW $[7,8]$. Previous reports showed that the mechanical properties and durability of RAC are generally worse than natural aggregate concrete (NAC) $[9,10]$; this mainly attributes to the microcrack [11] and adhered old mortar that exist in RCA $[12,13]$. In addition, several studies found that the performance of RAC is related to the replacement percentage [14], type [11, 15], size [13] of RCA, properties of interface transition zone (ITZ) [16], admixtures [17], etc. These characteristics of RCA and RAC all hinder its application in some areas.

To address this issue and improve the properties of RAC, several methods were applied to improve the properties of RAC these days [1,17-19], for instance, strengthening or removing the adhered old mortar of RCA $[15,20]$, applying a two-stage mixing approach, and introducing some mineral admixtures $[17,20]$. However, removing the adhered old mortar from RCA may cause microcracks, the enhancing effectiveness of adhered old. Fiber polymer has a super aspect ratio and can form bridge action when adding to concrete, which makes it possible to improve the properties of RAC [21-23].

These days, a large number of reports have confirmed that the addition of fiber is an effective tool to improve the properties of RAC [22, 24-26]. Niu et al. [21] investigated 
TABle 1: Properties of cement.

\begin{tabular}{|c|c|c|c|c|c|c|c|c|c|}
\hline \multicolumn{4}{|c|}{ Chemical composition (mass\%) } & \multicolumn{2}{|c|}{ Physical properties } & \multicolumn{2}{|c|}{$\begin{array}{c}\text { Flexural } \\
\text { strength } \\
(\mathrm{MPa})\end{array}$} & \multicolumn{2}{|c|}{$\begin{array}{l}\text { Compressive } \\
\text { strength } \\
(\mathrm{MPa})\end{array}$} \\
\hline $\mathrm{SiO}_{2}$ & $\mathrm{Al}_{2} \mathrm{O}_{3}$ & $\mathrm{FeO}$ & $\mathrm{CaO}$ & Specific gravity $\left(\mathrm{kg} / \mathrm{m}^{3}\right)$ & Specific surface $\left(\mathrm{m}^{2} / \mathrm{kg}\right)$ & $3 d$ & $28 \mathrm{~d}$ & $3 \mathrm{~d}$ & $28 \mathrm{~d}$ \\
\hline 18.7 & 5.9 & 3.4 & 61.9 & 3170.0 & 360.0 & 7.5 & 8.7 & 44.7 & 50.1 \\
\hline
\end{tabular}

the effect of BFs on the compressive strength of concrete (C30, C40, and C50) and found that the maximum increment in compressive strength was $9.18 \%$ (C30), 5.06\% (C40), and 7.13\% (C50), respectively. Caetano et al. [25] carried out an experiment to study the flexural strength of a high strength steel fiber concrete; results showed that the addition of steel fibers improving the fracture energy of concrete increases its ultimate flexural strength. Grzymski et al. [22] found that the concrete prepared with recycled steel fiber showed about six times lower efficiency in absorbing the energy after concrete matrix cracking, compared with a typical steel fibermodified concrete. Similar conclusion was also reported by Akça et al. [23]. To date, the studies of the effect of fiber on the properties of RAC mainly involve the mechanical properties and durability, while the effect of fiber on dynamic properties and chloride resistance of RAC is still limited. Steel fiber, as the most commonly used fiber to reinforce RAC, has a high bulk density and increases the self-weight of concrete structure [25]. Furthermore, steel fiber is susceptible to corrosion. These drawbacks all limit its application in some areas with requirements of antivibration and chloride corrosion resistance [25].

Damping is the ability to convert the vibration energy into other forms of energy during the vibration process [26, 27]. Previous investigations indicated the weak bond strength between the BFs and cement mortar in concrete; this characteristic may increase the energy dispersion [28]. Therefore, several studies investigated the dynamic characteristics of BF-reinforced RAC and pointed that the fiber-reinforced RAC leads to a higher damping ratio than that of the NAC, while adding BFs significantly reduced the mechanical performance of RAC [27]. PP has a higher elongation at break, approximately increased by 5-6 times than that of the BFs, which has potential possibilities to increase the dynamic properties of concrete [27]. Nowadays, the increasing application of various types of fibers in concrete makes the dynamic behavior of RAC even more complex. To date, the studies of the effect of PPs on the dynamic properties of RAC are still limited, especially in the comparative study of the dynamic characteristics of RAC modified with PPs and BFs.

In this study, for the first time, we compared the effects of fiber contents/types on the air void content, workability (slump), mechanical performance (compressive and flexural strength), dynamic characteristics (dynamic modulus of elasticity and damping ratio), and chloride resistance of RAC. Two types of RAC formulations were prepared: RAC reinforced with BFs and RAC reinforced with PPs. The experimental results showed the potential of using fiber to promote the damping ratio and flexible strength of RAC. It is greatly significant to further apply fiber in RAC.
TABle 2: Properties of FA.

\begin{tabular}{|c|c|c|c|c|c|c|c|}
\hline \multicolumn{4}{|c|}{$\begin{array}{l}\text { Chemical composition } \\
\text { (mass\%) }\end{array}$} & \multicolumn{2}{|c|}{$\begin{array}{c}\text { Physical } \\
\text { properties (\%) }\end{array}$} & \multicolumn{2}{|c|}{$\begin{array}{l}\text { Activity } \\
\text { index (\%) }\end{array}$} \\
\hline $\mathrm{CaO}$ & $\mathrm{SiO}_{2}$ & $\mathrm{Al}_{2} \mathrm{O}_{3}$ & $\mathrm{Fe}_{2} \mathrm{O}_{3}$ & Fineness & Loss & $7 \mathrm{~d}$ & $28 \mathrm{~d}$ \\
\hline 49.7 & 31.1 & 6.0 & 3.8 & 25.3 & 4.5 & 97.2 & 101.3 \\
\hline
\end{tabular}

\section{Materials and Experiments}

\subsection{Materials}

2.1.1. Cementitious Materials. Portland cement (P.O 42.5) and fly ash (FA) are used in this study. Tables 1 and 2 present the properties of cement and FA, respectively. Which complied with the requirements of the Chinese National Standards GB175-2007 [29] and GB/T 1596-2005 [30], respectively.

2.1.2. Aggregates. Crushed limestone with a continuous grading is used as coarse aggregate (Figure 1) in this study. The aggregate has the maximum size of $19 \mathrm{~mm}$, and Table 3 presents the properties of coarse aggregate. The fine aggregate used was river sand. It has a water absorption of $1.14 \%$ and fineness modulus of 2.60, respectively. The properties of corsage and fine aggregate complied with the Chinese National Standards GB/T 14685-2011 [31] and GB/T14684-2011 [32], respectively.

2.1.3. Fiber Polymer and Additive. The PPs and BFs were used to improve the dynamic properties of RAC. Table 4 presents the properties of fiber. Polycarboxylate-based superplasticizer (SP) was used in this study, and the solid content and water-reducing ratio of the SP is $35 \%$ and $28 \%$, respectively.

2.2. Mixture Proportions. To compare the effects of fiber contents/types and replacement percentage of RCA on the air void content, workability, mechanical properties, dynamic characteristics, and chloride resistance of RAC. Nine different mix proportions were considered in this study.

Tables 5 and 6 show the mix proportions of the reference concrete and RAC, respectively. The addition of fiber polymer was at volume content of $0.0-0.3 \%$, respectively. The mixtures were named as follow: take the 50RAC-PP-0.1 for instance, 50RAC refers to the replacement percentage of RAC which is $50.0 \%$, and the PP-0.1 refers to the amount of PPs which is $0.1 \%$. The tap water consists of two parts: the water consumption of ordinary concrete mix design and the additional water. It should be noted that the additional water does not change the effective water-to-binder ratio of the mixture. 

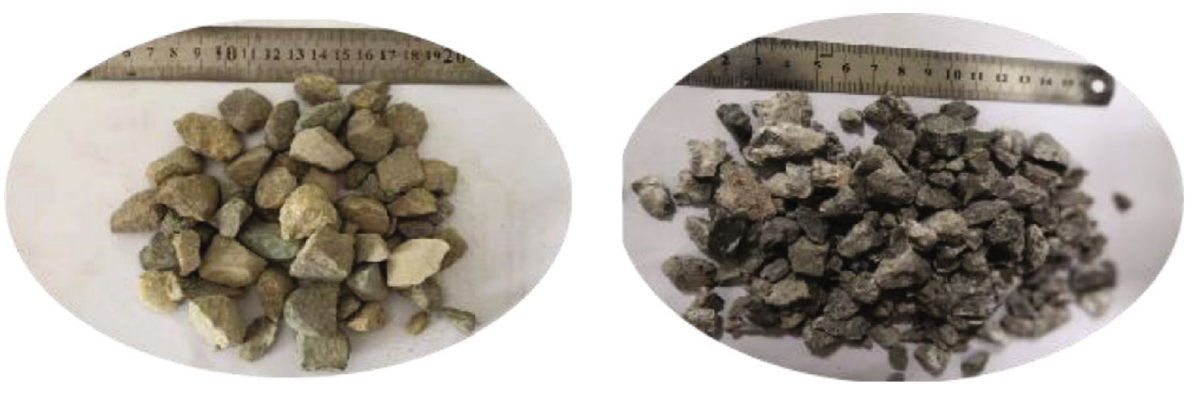

FIGURE 1: Coarse aggregate used in this study: NCA and RCA.

Table 3: Properties of RCA and NCA.

\begin{tabular}{lcccc}
\hline Type & Crushing value index $(\%)$ & Apparent density $\left(\mathrm{kg} / \mathrm{m}^{3}\right)$ & Bulk density $\left(\mathrm{kg} / \mathrm{m}^{3}\right)$ & Water absorption $(\%)$ \\
\hline NCA & 9.8 & 2561.0 & 1380.0 & 1.1 \\
RCA & 15.7 & 2509.0 & 1253.0 & 5.5 \\
\hline
\end{tabular}

TABle 4: Properties of PPs and BFs.

\begin{tabular}{lccccc}
\hline Laber & Diameter $(\mu \mathrm{m})$ & Density $\left(\mathrm{kg} / \mathrm{m}^{3}\right)$ & Elastic modulus $(\mathrm{GPa})$ & Elongation $(\%)$ & Tensile strength $(\mathrm{MPa})$ \\
\hline $\mathrm{PP}$ & 32.0 & 920.0 & 3.8 & 20.0 & 450.5 \\
$\mathrm{BF}$ & 17.0 & 2590.0 & 89.1 & 2.9 & 2670.0 \\
\hline
\end{tabular}

TABLE 5: Mix proportion of reference concrete $\left(\mathrm{kg} / \mathrm{m}^{3}\right)$.

\begin{tabular}{lccccc}
\hline Cement & Fly ash River sand & $\begin{array}{c}\text { Natural } \\
\text { aggregate }\end{array}$ & Water & Additive \\
\hline 425.0 & 75.0 & 700.0 & 1050.0 & 165.0 & 5.0 \\
\hline
\end{tabular}

TABLE 6: Mix proportions of reference concrete and RAC.

\begin{tabular}{lccccc}
\hline & \multicolumn{2}{c}{$\begin{array}{c}\text { Volume } \\
\text { content of }\end{array}$} & \multicolumn{2}{c}{ Coarse } \\
Concrete ID & fiber (\%) & \multicolumn{2}{c}{ agregate (\%) } & Water (kg) \\
& PP & BF & NA & RA & \\
\hline R & 0.0 & 0.0 & 0.0 & 0.0 & $165(0)$ \\
50RAC & 0.0 & 0.0 & 50.0 & 50.0 & $165(23.2)$ \\
100RAC & 0.0 & 0.0 & 100.0 & 100.0 & $165(46.4)$ \\
50RAC-PP-0.1 & 0.1 & 0.0 & 50.0 & 50.0 & $165(23.2)$ \\
50RAC-PP-0.2 & 0.2 & 0.0 & 50.0 & 50.0 & $165(23.2)$ \\
50RAC-PP-0.3 & 0.3 & 0.0 & 50.0 & 50.0 & $165(23.2)$ \\
50RAC-BF-0.1 & 0.0 & 0.1 & 50.0 & 50.0 & $165(23.2)$ \\
50RAC-BF-0.2 & 0.0 & 0.2 & 50.0 & 50.0 & $165(23.2)$ \\
50RAC-BF-0.3 & 0.0 & 0.3 & 50.0 & 50.0 & $165(23.2)$ \\
\hline
\end{tabular}

\subsection{Test Methods}

2.3.1. Air Void Content. A concrete air void content measuring instrument (LC 61-7L) was used to test the air void content of fresh concrete according to the Chinese National Standard GB/T 50080-2016 [33].

2.3.2. Workability. The slump value was applied to measure workability of fresh RAC according to the Chinese National Standard GB/T 50080-2016 [33].
2.3.3. Mechanical Performance. For the compressive and flexural strength test, the cubic specimens with a dimension of $150 \mathrm{~mm} \times 150 \mathrm{~mm} \times 150 \mathrm{~mm}$ and prismatic specimens with a dimension of $100 \mathrm{~mm} \times 100 \mathrm{~mm} \times 400 \mathrm{~mm}$ were used, respectively. After 24 hours from the initial casting, the samples were demolded and then kept for 7 and 28 days at a curing room $\left(20 \pm 1{ }^{\circ} \mathrm{C}, \geq 95 \% \mathrm{RH}\right)$ until the day of the test, in accordance with the Chinese National Standard GB/T 50081-2002 [34].

2.3.4. Dynamic Properties. For the dynamic modulus of the elasticity test, samples with a dimension of $100 \mathrm{~mm} \times 100$ $\mathrm{mm} \times 400 \mathrm{~mm}$ were used after 28 days of curing according to the Chinese National Standard GB/T 50082-2009 [35], which were obtained by the transverse resonant frequent method and the result obtained by the average three individual test results, which were calculated by

$$
E_{d}=13.244 \times 10^{-4} \times \frac{W L^{3} f^{2}}{\alpha^{4}}
$$

where $E_{d}$ is the dynamic modulus of elasticity of concrete, $\mathrm{MPa} ; W$ is the weight of sample, $\mathrm{kg} ; L$ is the length of test sample, $\mathrm{mm} ; f$ is the transverse frequency of the specimen, $\mathrm{Hz} ; \alpha$ is the side length of square cross-section sample, $\mathrm{mm}$.

The damping ratio was used to define the damping capacity of concrete. A free-free beam vibration and pulse hardware/software (Brüel \& Kjær) were used to test the damping ratio of concrete according to Tian et al. [26]. Figures 2 and 3 show the acceleration history of free vibration of the RAC and the resonance curves, respectively. All specimens for the damping ratio test were after 28 days of curing, and the samples with the dimension of $100 \mathrm{~mm} \times 100 \mathrm{~mm}$ 

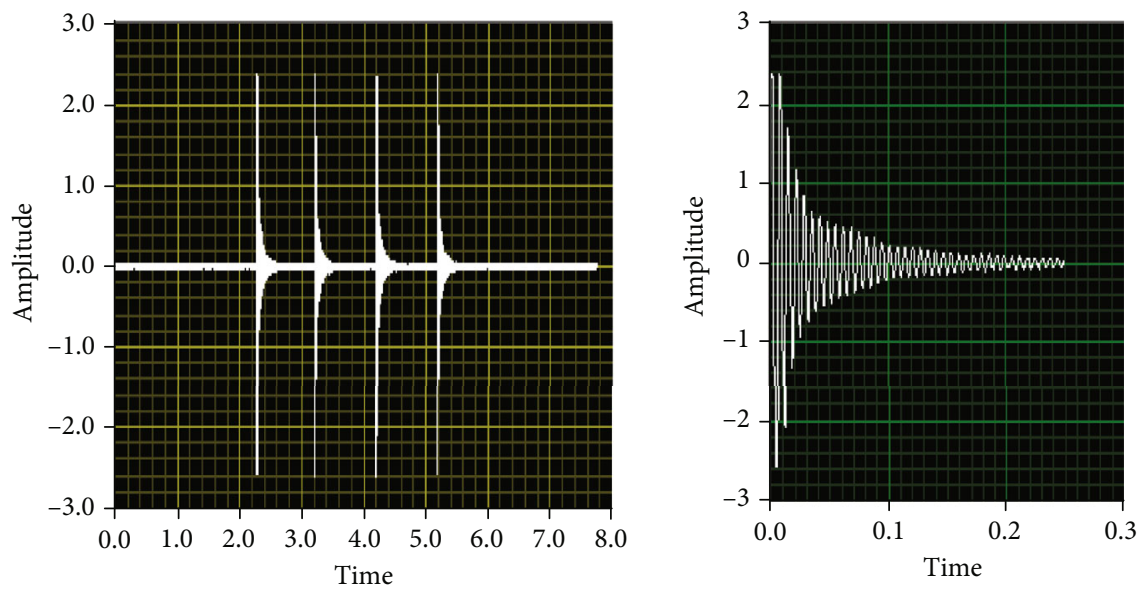

Figure 2: Acceleration response signals as time magnitude.

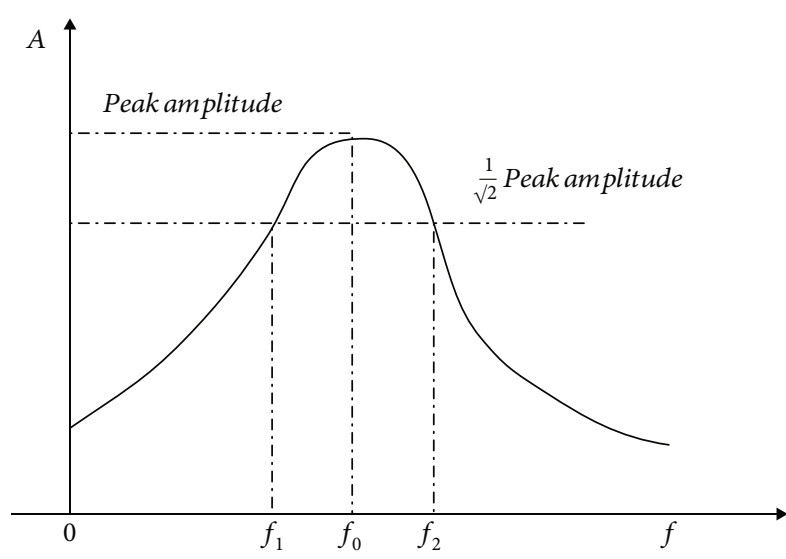

Figure 3: The half-power bandwidth method for the estimation damping ratio of concrete [26].

$\times 400 \mathrm{~mm}$. The damping ratio of concrete was calculated by the half-power bandwidth method, which was calculated by

$$
\xi=\frac{\left(f_{1}-f_{2}\right)}{2 f_{0}},
$$

where $\zeta$ represents the damping ratio of RAC, $\% ; f_{1}$ and $f_{2}$ represent the frequencies corresponding to an amplitude of $f_{0} / \sqrt{ } 2, \mathrm{~Hz} ; f_{0}$ represents the resonant frequency of RAC, $\mathrm{Hz}$.

2.3.5. Chloride Resistance. The rapid chloride migration method (RCM) was applied to evaluate the chloride resistance of concrete after 28 days of curing according to the Chinese National Standard GB/T 50082-2009 [35]. Figure 4 presents the test process of chloride resistance of concrete.

2.3.6. Microstructure Characterizations. The microstructure of concrete was characterized by a S-4800 environmental scanning electron microscope (ESEM). After 28 days of curing, the specimens were broken into small pieces and selected for sample preparation. It should be noted that the surface of specimens was coated by gold before testing.

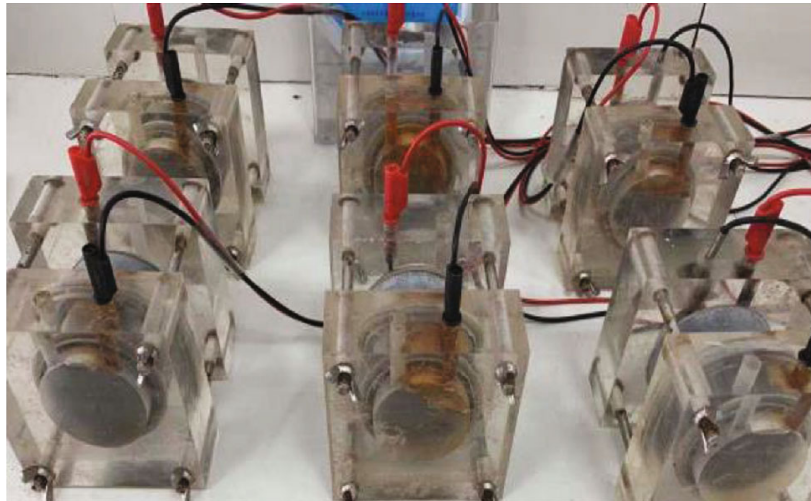

FIgURE 4: Test process of the chloride resistance of concrete.

\section{Results and Discussion}

3.1. Air Void Content. Figure 5 shows the air void content value of fresh concrete. It can be observed that the addition of fiber had a significant influence on the air void content of RAC. The air void content of RAC slightly decreased by $15.8 \% \quad$ (50RAC-PP-0.1), 21.1\% (50RAC-PP-0.2), $5.3 \%$ (50RAC-BF-0.1), $\quad 15.8 \%$ (50RAC-BF-0.2), and $21.1 \%$ (50RAC-BF-0.3) in each case, compared with 50RAC. Only the mixture 50RAC-PP- 0.3 containing $0.3 \%$ PPs significantly reduced by $31.6 \%$.

The addition of RCA had no significant influence on air void content when replacement percentage of RCA is less than $50 \%$, while a sharp reduction of air void content could be found at $100 \%$ RCA mixture (100RAC). Compared to the reference concrete, the air void content value of fresh RAC decreased by $17.4 \%$ (50RAC) and 26.1\% (100RAC), respectively. It can be obtained that the addition of RAC in reducing the air void content of RAC was more obvious than that of the addition of fiber.

3.2. Workability. From Figure 6, it can be observed that the slump value decreased by $16.7 \%$ (50RAC) and $41.7 \%$ (100RAC), respectively, compared with the reference concrete. Further, the mixtures with the addition of PPs 


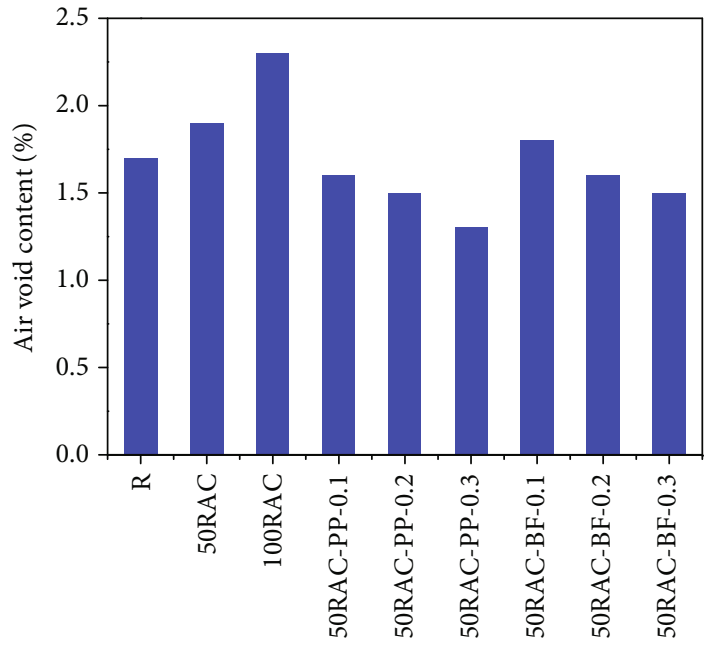

Concrete ID

Figure 5: Air void content value of fresh concrete.

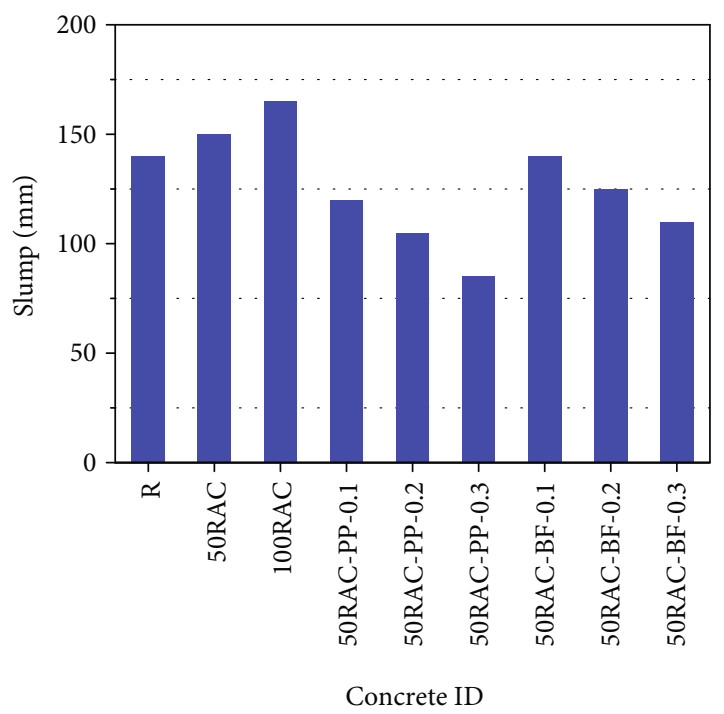

Figure 6: Slump of fresh concrete.

(50RAC-PP-0.1, 50RAC-PP-0.2, and 50RAC-PP-0.3) obtained the relative lower slump value. In addition, the slump value of RAC decreased with the increase of PP or $\mathrm{BF}$ content. There is no significant influence when the PP or $\mathrm{BF}$ content less than $0.2 \%$, while a significant reduction of slump could be observed on the mixture with $0.3 \%$ fiber. The slump value of mixtures 50RAC-PP-0.3 and 50RACBF- 0.3 decreased by $43.3 \%$ and $26.7 \%$, respectively, compared to 50RAC. This is mainly attributed to the fiber that has a high surface area with a high water absorption rate $[36,37]$, increasing the viscosity of fresh concrete. Therefore, the recommended dosage of fiber is below $0.2 \%$ to obtain a relatively good workability of mixture. Further, results indicated that the addition PPs provided a more negative effect on the slump of RAC than that of the BFs.

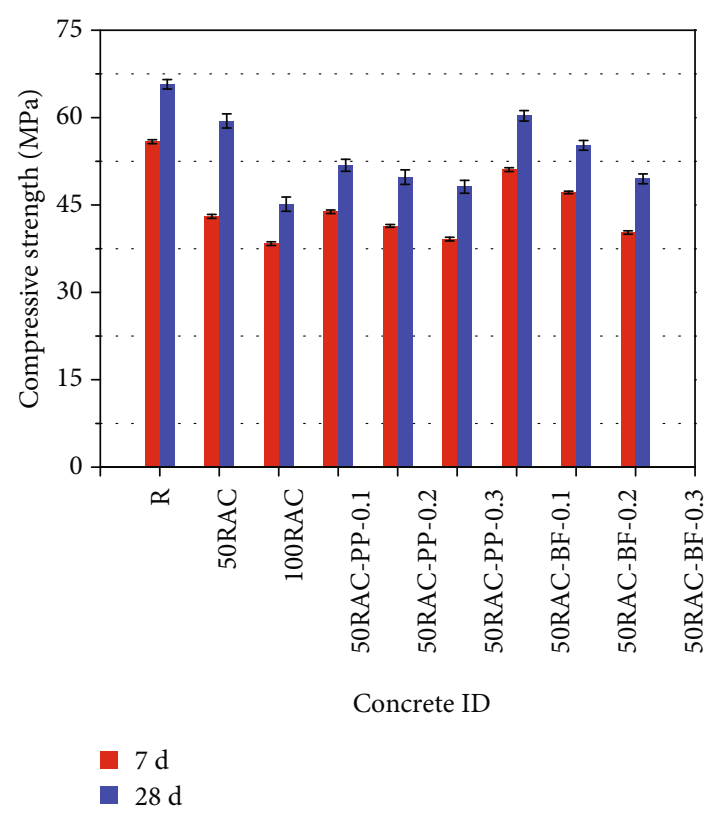

Figure 7: Compressive strength of concrete.

3.3. Mechanical Properties. From Figure 7, it can be obtained that the compressive strength of specimens decreased by 9.6\% (50RAC) and 31.2\% (100RAC), respectively, after 28 days of curing, compared with the reference concrete. This could be attributed to the adhered old mortar on RCA which has a large number of pores and microcracks [13], resulting in a poor properties of RCA than that of the NCA (as seen in Table 3). It needed to be highlighted that the increment of the replacement percentage of RCA could consequently increase the number of pores and cracks; thus, the compressive strength of RAC decreased with the increase of replacement percentage of RCA [16]. Similar conclusion has been reported by Wijayasundara et al. [3].

The compressive strength of RAC significantly decreased by $12.9 \%$ (50RAC-PP-0.1), 16.2\% (50RAC-PP-0.2), 5.3\% (50RAC-PP-0.3), $19.4 \%$ (50RAC-BF-0.2), and $15.9 \%$ (50RAC-BF-0.3) in each case compared to that of 50RAC. Only the compressive strength of mixture 50RAC-BF-0.1 slightly increased by $1.5 \%$ after 28 days of curing. The results were consistent with the previous reports [36]. The reduction of compressive could be summarized as follows: (1) the addition of fiber brings many defects, such as bubbles, voids, and loose matrix [13]. These defects form a weak ITZ between fiber and mortar and have high porosity and a large number of microcracks [13, 36]; (2) the addition of fiber may be agglomerated when it appears to uneven dispersion, and then, it could form a defect and reduce the compressive strength of RAC [13]; (3) the addition of fiber can form a dimensional network structure; it can dissipate stress and overcome the relative slip between the particles [13]; and (4) the addition of fibers play a role in bridge action, which can prevent the propagation of microcracks [36]. Based on the above, the compressive strength of RAC reinforced with fiber showed a slight reduction or increment, compared to the reference concrete. The weak ITZ between fiber and 


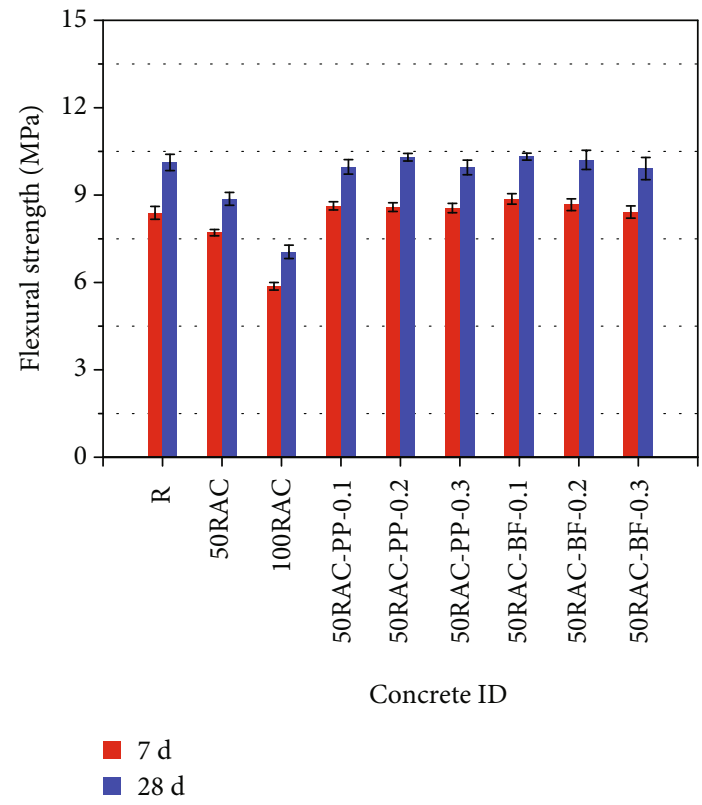

Figure 8: Flexural strength of concrete.

mortar, bubbles, voids, and loose matrix due to the addition of fiber had the potential to increase the damping ratio of RAC with the addition of fiber; this will be discussed in Section 3.4

The effect of addition of fibers or RCA on the flexural strength of RAC was obvious. Compared to the reference concrete after 28 days of curing, the flexural strength of mixtures 50RAC and 100RAC decreased by $12.4 \%$ and $30.1 \%$, respectively, as seen in Figure 8 . It also can be observed that the flexural strength of RAC increased by $11.9 \%$ (50RACPP-0.1), 16.1\% (50RAC-PP-0.2), and 12.2\% (50RAC-PP0.3 ) in each case compared to that of the 50RAC. And the mixtures containing $0.1 \%, 0.2 \%$, and $0.3 \% \mathrm{BFs}$, the flexural strength of concretes increased by $15.1 \%, 16.4 \%$, and $11.7 \%$, respectively. That is to say, the mixtures containing $0.2 \%$ PPs and BFs both obtained the highest flexural strength. This result was consistent with the previous reports [36]. This could be attributed to the bridge action of fiber [36]. Therefore, the recommended dosage of fiber is $0.2 \%$ to obtain the highest flexural strength.

\subsection{Dynamic Characteristics}

3.4.1. Dynamic Modulus of Elasticity. Figure 9 shows the dynamic modulus of elasticity of concrete; it can be observed that the dynamic modulus of elasticity of the specimens 50RAC and 100RAC decreased by $6.6 \%$ and $19.1 \%$, respectively, compared to that of the reference concrete after 28 days of curing.

The dynamic modulus of elasticity of RAC reinforced with PPs decreased by 5.1\% (50RAC-PP-0.1), 9.3\% (50RAC-PP-0.2), and 9.9\% (50RAC-PP-0.3) in each case compared to that of the 50RAC, as seen in Figure 9, while the dynamic modulus of elasticity of BF-reinforced RAC decreased by $2.2 \%$ (50RAC-BF-0.1), 7.3\% (50RAC-BF-0.2),

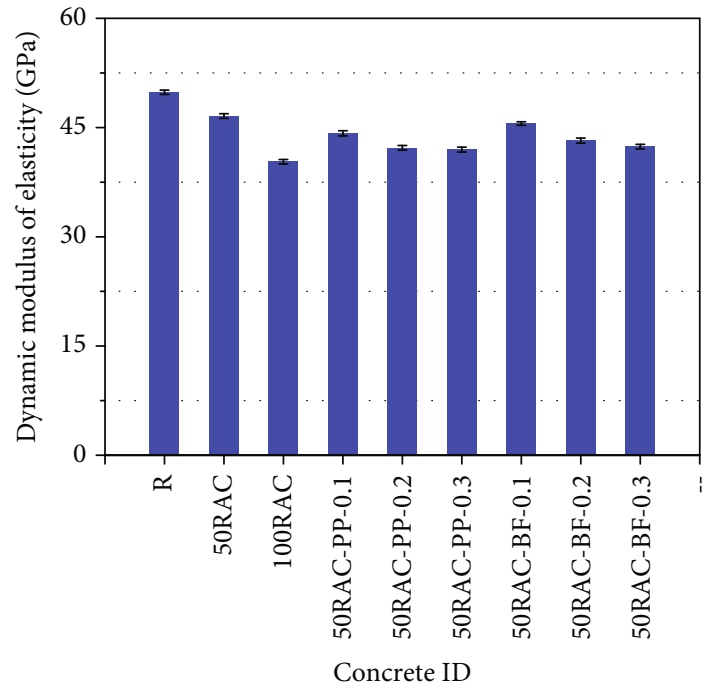

FIgURe 9: Dynamic modulus of elasticity of concrete.

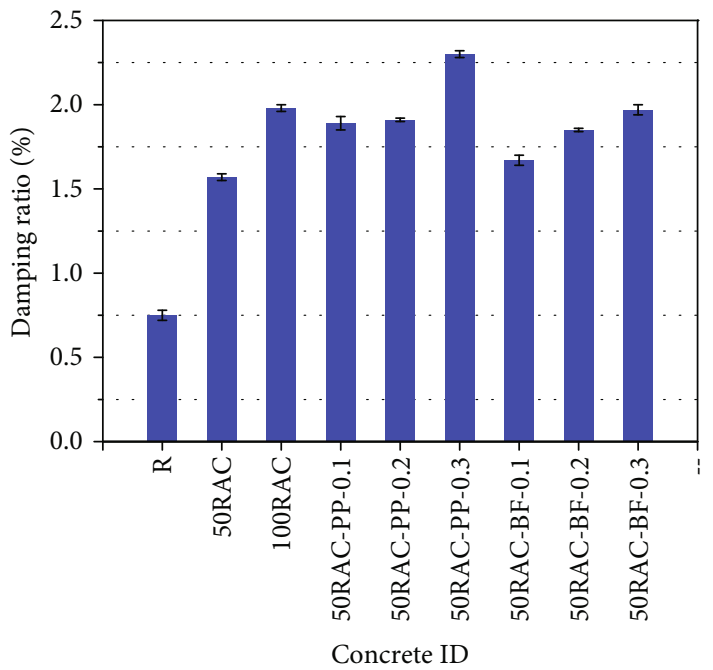

FIGURE 10: Damping ratio of concrete.

and 9.1\% (50RAC-BF-0.3), respectively. The effect of fiber on the dynamic modulus of elasticity of RAC was similar to that of the compressive strength. It can be concluded that the addition of BFs was more effective than that of PPs for increasing the dynamic modulus of elasticity of concrete.

3.4.2. Damping Ratio. From Figure 10, it can be observed that the damping ratio of mixtures (50RAC and 100RAC) after 28 days of curing increased to $1.6 \%$ and $2.0 \%$, respectively. That is, the damping ratio of RAC increased by $109.3 \%$ (50RAC) and $164.0 \%$ (100RAC), respectively, compared to that of the reference concrete. Results showed that the damping ratio of RAC (50RAC and 100RAC) approximately increased by 1.5-2.0 times than that of the reference concrete.

The improvement in the damping ratio of the fiberreinforced RAC can be summarized as follows: (1) the adhered old mortar of RCA and the ITZs (old and new ITZ) exists substantial number of voids [13, 38], as shown 


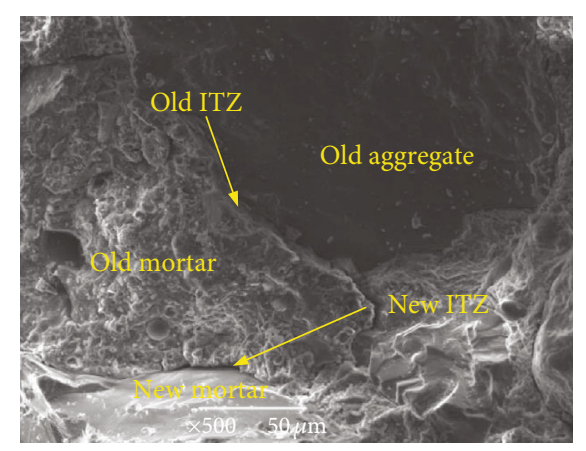

(a)

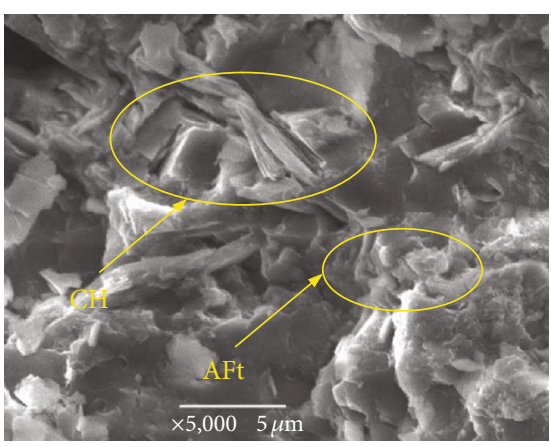

(b)

FIGURE 11: Microstructure of RAC: (a) classification ITZs of RAC and (b) hydration products.

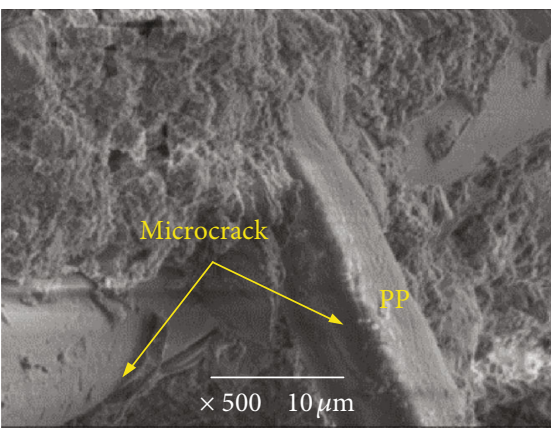

(a)

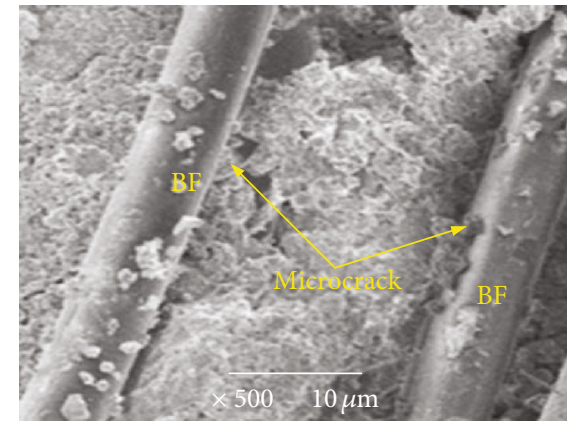

(b)

Figure 12: ITZ between the fiber-mortar (a) PP-mortar and (b) BF-mortar.

in Figure 11, the expansion and contraction of the air in voids conducive to the energy dissipation in RAC [13]; (2) the disperse energy by the friction of microcracks exists in ITZs; additionally, the porous ITZs have a large number of hydration products ( $\mathrm{CH}$ crystals and $\mathrm{AFt}$ ), leading to a high porosity and looser microstructure, which provided a positive influence on the energy dissipation of concrete [16, 39]; (3) the existence of old mortar (Figure 11) is conducive to energy dissipation due to the sliding friction between the old and new mortar [13]; and (4) the sliding friction between the fiber and the mortar. Therefore, the damping ratio of RAC increased with the increase of the replacement ratio of RCA. Correspondingly, the characteristics of weaken ITZ have a negative effect on the mechanical properties of RAC, as illustrated in Section 3.3.

The damping ratio of concretes increased by $152.04 \%$ (50RAC-PP-0.1), 154.7\% (50RAC-PP-0.2), and 206.7\% (50RAC-PP-0.3), respectively, while increased by $122.7 \%$ (50RAC-BF-0.1), $146.7 \%$ (50RAC-BF-0.2), and $162.7 \%$ (50RAC-BF-0.3), respectively, compared to that of the 50RAC, as seen in Figure 10. Results indicated that the addition of fibers had a positive effect on the damping ratio of RAC, especially the addition of PPs; this could be attributed to the weak ITZ between fiber and mortar (Figure 12). Therefore, the recommended dosage of fiber was $0.3 \%$ to obtain the highest damping ratio. Further, results indicated that the addition of PPs was more effective than that of BFs in improving the damping ratio of RAC.

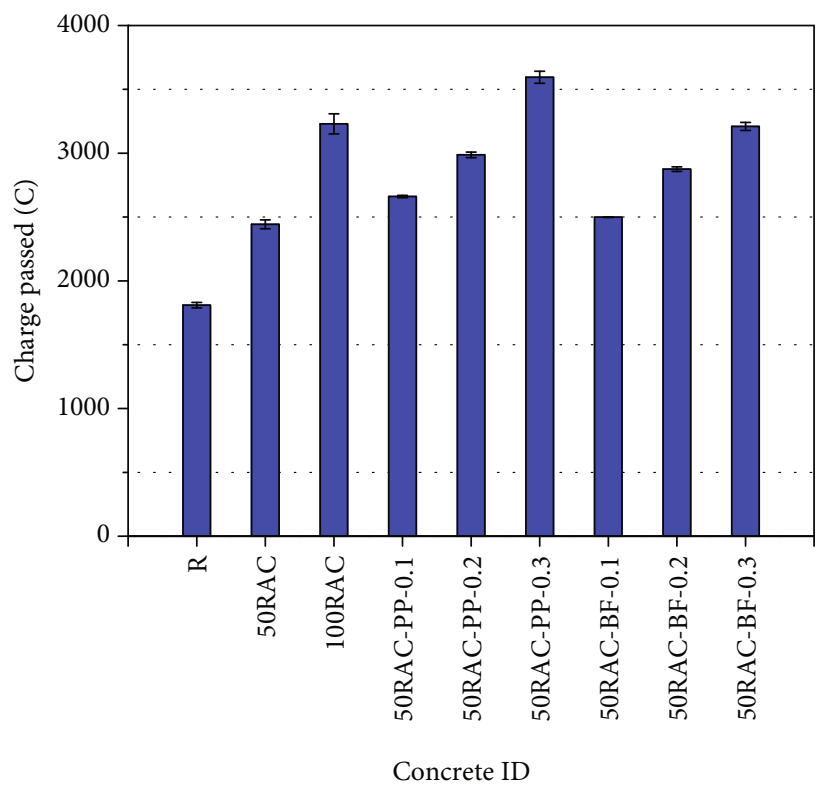

Figure 13: Charge passed of concrete after 28 days of curing.

3.5. Chloride Resistance. From Figure 13, it can be seen that the charge passed increased with the increase of replacement rate of RCA; the charge passed of concrete was $2443.0 \mathrm{C}$ and $3230.3 \mathrm{C}$, respectively. The maximum charge passed of 
mixture belonged to the specimen containing 100\% RCA (100RAC).

Compared to the 50RAC after 28 days of curing, the charge passed of RAC with the addition of PPs with 0.1 $0.3 \%$ contents approximately increased by $8.9-47.2 \%$, while the addition of BFs with $0.1-0.3 \%$ contents increased by 2.3-31.4\%. The observation was well agreed by the previous studies [23, 25, 36]. The increment in charge passed of RAC reinforced with $\mathrm{PPs}$ and BFs could be attributed to the defects in concrete (ITZ between the fiber-mortar and voids) [40]. Further, the charge passed of specimens with the addition of PPs was greater than that of the specimens with the addition of BFs.

\section{Conclusions}

In this paper, we prepared two types of RAC formulations: $\mathrm{RAC}$ reinforced with BFs and $\mathrm{RAC}$ reinforced with PPs, and compared the effects of fiber types and contents on the air void content, workability (slump), mechanical properties (compressive and flexural strength), dynamic characteristics (dynamic modulus of elasticity and damping ratio), and chloride resistance of RAC. With the test results presented in this study, the following conclusions can be drawn:

(1) The addition of fiber leads to a reduction of air void content and slump of RAC. The air void content decreased by $15.8 \%$ (50RAC-PP-0.1), $21.1 \%$ (50RAC-PP-0.2), $\quad 5.3 \% \quad$ (50RAC-BF-0.1), $15.8 \%$ (50RAC-BF-0.2), and 21.1\% (50RAC-BF-0.3) in each case, compared with 50RAC. The addition of PPs provided a more negative effect on the slump than that of the BFs; the slump of mixtures 50RAC-PP0.3 and 50RAC-BF-0.3 decreased by $43.3 \%$ and $26.7 \%$, respectively

(2) The contents and types of fiber here had marginal effects on the compressive strength of concrete, while the flexural strength of RAC had been significantly influenced. The flexural strength of RAC increased by $11.9 \%$ (50RAC-PP-0.1), 16.1\% (50RAC-PP-0.2), and $12.2 \%$ (50RAC-PP-0.3) in each case compared to that of the 50RAC. And the mixtures containing $0.1 \%, 0.2 \%$, and $0.3 \% \mathrm{BFs}$, the flexural strength of concretes increased by $15.1 \%, 16.4 \%$, and $11.7 \%$, respectively. The recommended dosage of fiber is $0.2 \%$ to obtain the highest flexural strength

(3) The damping ratio of concretes (50RAC and 100RAC) approximately increased by 1.5-2.0 times than that of the reference concrete. The addition of PPs was more effective than that of BFs in improving the damping ratio of RAC, and the specimens containing $0.3 \%$ fiber obtained the highest damping ratio value; the damping ratio of concretes increased by 206.7\% (50RAC-PP-0.3) and 162.7\% (50RAC-BF0.3 ), respectively, compared to that of the 50RAC

(4) The charge passed of specimens with the addition of PPs was greater than that of the specimens with the addition of BFs. Compared to the 50RAC after 28 days of curing, the charge passed of specimen addition of PPs approximately increased by $45 \%$, while the specimen addition of BFs approximately increased by $30 \%$, when the fiber content was $0.3 \%$

\section{Data Availability}

The data used to support the findings of this study are included within the article.

\section{Conflicts of Interest}

The authors declare that they have no conflicts of interest.

\section{Acknowledgments}

This research was supported by the 2018 Nantong Basic Science Research Project (JC2018096) and the Natural Science Fund for Colleges and Universities in Jiangsu Province (17KJB580009).

\section{Supplementary Materials}

Table 1 Air void content and slump value of concrete. Table 2 Mechanical properties of concrete. Table 3 Dynamic properties of concrete. Table 4 Charge passed of concrete. (Supplementary Materials)

\section{References}

[1] V. W. Y. Tam, A. Butera, and K. N. Le, "Carbon-conditioned recycled aggregate in concrete production," Journal of Cleaner Production, vol. 133, pp. 672-680, 2016.

[2] J. J. Xu, Z. P. Chen, T. Ozbakkaloglu, X. Y. Zhao, and C. Demartino, "A critical assessment of the compressive behavior of reinforced recycled aggregate concrete columns," Engineering Structures, vol. 161, pp. 161-175, 2018.

[3] M. Wijayasundara, R. H. Crawford, and P. Mendis, "Comparative assessment of embodied energy of recycled aggregate concrete," Journal of Cleaner Production, vol. 152, pp. 406419, 2017.

[4] Y. L. Chen, Z. P. Chen, J. J. Xu, E. M. Lui, and B. Wu, "Performance evaluation of recycled aggregate concrete under multiaxial compression," Construction and Building Materials, vol. 229, article 116935, 2019.

[5] B. Qi, J. Gao, F. Chen, and D. Shen, "Evaluation of the damage process of recycled aggregate concrete under sulfate attack and wetting-drying cycles," Construction and Building Materials, vol. 138, pp. 254-262, 2017.

[6] N. K. Bui, T. Satomi, and H. Takahashi, "Improvement of mechanical properties of recycled aggregate concrete basing on a new combination method between recycled aggregate and natural aggregate," Construction and Building Materials, vol. 148, pp. 376-385, 2017.

[7] R. L. Al-Mufti and A. N. Fried, "Improving the strength properties of recycled asphalt aggregate concrete," Construction and Building Materials, vol. 149, pp. 45-52, 2017.

[8] A. Koper, W. Koper, and M. Koper, "Influence of raw concrete material quality on selected properties of recycled concrete aggregates," Process Engineering, vol. 172, pp. 536-543, 2017. 
[9] J. Wang, B. Vandevyvere, S. Vanhessche, J. Schoon, N. Boon, and N. De Belie, "Microbial carbonate precipitation for the improvement of quality of recycled aggregates," Journal of Cleaner Production, vol. 156, pp. 355-366, 2017.

[10] M. Wijayasundara, P. Mendis, and R. H. Crawford, "Methodology for the integrated assessment on the use of recycled concrete aggregate replacing natural aggregate in structural concrete," Journal of Cleaner Production, vol. 166, pp. 321334, 2017.

[11] E. Vázquez, M. Barra, D. Aponte, C. Jiménez, and S. Valls, "Improvement of the durability of concrete with recycled aggregates in chloride exposed environment," Construction and Building Materials, vol. 67, pp. 61-67, 2014.

[12] D. Xuan, B. Zhan, and C. S. Poon, "Durability of recycled aggregate concrete prepared with carbonated recycled concrete aggregates," Cement and Concrete Composites, vol. 84, pp. 214-221, 2017.

[13] C. Liang, T. Liu, J. Xiao, D. Zou, and Q. Yang, "The damping property of recycled aggregate concrete," Construction and Building Materials, vol. 102, pp. 834-842, 2016.

[14] C. Zhou and Z. Chen, "Mechanical properties of recycled concrete made with different types of coarse aggregate," Construction and Building Materials, vol. 134, pp. 497-506, 2017.

[15] L. Li, C. S. Poon, J. Xiao, and D. Xuan, "Effect of carbonated recycled coarse aggregate on the dynamic compressive behavior of recycled aggregate concrete," Construction and Building Materials, vol. 151, pp. 52-62, 2017.

[16] K. Liao, P. Chang, Y. Peng, and C. Yang, "A study on characteristics of interfacial transition zone in concrete," Cement and Concrete Research, vol. 34, no. 6, pp. 977-989, 2004.

[17] Z. Tahar, T. Ngo, E. H. Kadri, A. Bouvet, F. Debieb, and S. Aggoun, "Effect of cement and admixture on the utilization of recycled aggregates in concrete," Construction and Building Materials, vol. 149, pp. 91-102, 2017.

[18] D. Lu, Z. Tang, L. Zhang et al., "Effects of combined usage of supplementary cementitious materials on the thermal properties and microstructure of high-performance concrete at high temperatures," Materials, vol. 13, no. 8, p. 1833, 2020.

[19] T. Y. Xie, G. S. Yang, X. Y. Zhao, J. J. Xu, and C. F. Fang, “A unified model for predicting the compressive strength of recycled aggregate concrete containing supplementary cementitious materials," Journal of Cleaner Production, vol. 251, article 119752, 2020.

[20] K. Pandurangan, A. Dayanithy, and S. Om Prakash, "Influence of treatment methods on the bond strength of recycled aggregate concrete," Construction and Building Materials, vol. 120, pp. 212-221, 2016.

[21] D. Niu, D. Huang, and Q. Fu, "Experimental investigation on compressive strength and chloride permeability of fiberreinforced concrete with basalt-polypropylene fibers," Advances in Structural Engineering, vol. 22, no. 10, pp. 2278-2288, 2019.

[22] F. Grzymski, M. Musiał, and T. Trapko, "Mechanical properties of fibre reinforced concrete with recycled fibres," Construction and Building Materials, vol. 198, pp. 323-331, 2019.

[23] K. R. Akça, Ö. Çakır, and M. İpek, "Properties of polypropylene fiber reinforced concrete using recycled aggregates," Construction and Building Materials, vol. 98, pp. 620-630, 2015.

[24] V. T. Giner, S. Ivorra, F. J. Baeza, E. Zornoza, and B. Ferrer, "Silica fume admixture effect on the dynamic properties of concrete," Construction and Building Materials, vol. 25, no. 8, pp. 3272-3277, 2011.
[25] H. Caetano, J. P. C. Rodrigues, and P. Pimienta, "Flexural strength at high temperatures of a high strength steel and polypropylene fibre concrete," Construction and Building Materials, vol. 227, p. 116721, 2019.

[26] Y. Tian, S. Shi, K. Jia, and S. Hu, "Mechanical and dynamic properties of high strength concrete modified with lightweight aggregates presaturated polymer emulsion," Construction and Building Materials, vol. 93, pp. 1151-1156, 2015.

[27] T. Li, J. Xiao, T. Sui, C. Liang, and L. Li, "Effect of recycled coarse aggregate to damping variation of concrete," Construction and Building Materials, vol. 178, pp. 445-452, 2018.

[28] F. Abed and A. R. Alhafiz, "Effect of basalt fibers on the flexural behavior of concrete beams reinforced with BFRP bars," Composite Structures, vol. 215, pp. 23-34, 2019.

[29] Ministry of Housing and Urban-Rural Development of the People's Republic of China, Common Portland cement (GB1752007), China Architecture and Building Press, Beijing, 2007.

[30] Ministry of Housing and Urban-Rural Development of the People's Republic of China, Fly ash used for cement and concrete (GB/T1596-2005), China Architecture and Building Press, Beijing, 2005.

[31] Ministry of Housing and Urban-Rural Development of the People's Republic of China, Pebble and crushed stone for construction (GB/T14685-2011), China Architecture and Building Press, Beijing, 2011.

[32] Ministry of Housing and Urban-Rural Development of the People's Republic of China, Sand for construction (GB/T 14684-2011), China Architecture and Building Press, Beijing, 2011.

[33] Ministry of Housing and Urban-Rural Development of the People's Republic of China, Standard for test method of performance on ordinary fresh concrete (GB/T 50080-2016), China Architecture and Building Press, Beijing, 2016.

[34] Ministry of Housing and Urban-Rural Development of the People's Republic of China, Standard for test method of mechanical properties on ordinary concrete (GB/T 500812002), China Architecture and Building Press, Beijing, 2002.

[35] Ministry of Housing and Urban-Rural Development of the People's Republic of China, Standard for test method of longterm performance and durability of ordinary concrete (GB/T 50082-2009), China Architecture and Building Press, Beijing, 2009.

[36] X. Hu, Y. Guo, J. Lv, and J. Mao, “The mechanical properties and chloride resistance of concrete reinforced with hybrid polypropylene and basalt fibres," Materials, vol. 12, no. 15, article 2371, 2019.

[37] O. H. Wallevik and J. E. Wallevik, "Rheology as a tool in concrete science: the use of rheographs and workability boxes," Cement and Concrete Research, vol. 41, no. 12, pp. 1279-1288, 2011.

[38] K. S. Lee, J. Choi, S. Kim, B. Lee, J. Hwang, and B. Y. Lee, "Damping and mechanical properties of composite composed of polyurethane matrix and preplaced aggregates," Construction and Building Materials, vol. 145, pp. 68-75, 2017.

[39] A. Parghi and M. S. Alam, "A review on the application of sprayed-FRP composites for strengthening of concrete and masonry structures in the construction sector," Composite Structures, vol. 187, pp. 518-534, 2018.

[40] J. J. Xu, Z. P. Chen, Y. Xiao, C. Demartino, and J. H. Wang, "Recycled aggregate concrete in FRP-confined columns: a review of experimental results," Composite Structures, vol. 174, pp. 277-291, 2017. 